Journal of Bangladesh Academy of Sciences, Vol. 34, No. 1, 33-48, 2010

\title{
TREND AND SPATIAL DISTRIBUTION OF AIR PARTICULATE MATTER POLLUTION IN DHAKA CITY
}

\author{
BILKIS A. BEGUM, SWAPAN K. BISWAS* AND M. NASIRUDDIN ${ }^{1}$
}

Atomic Energy Centre, P.O. Box 164, Dhaka-1000, Bangladesh

\begin{abstract}
From the air particle (PM) collected from different locations of Dhaka city it has been found that about $30-50 \%$ of the $\mathrm{PM}_{10}$ mass (depending on location) is fine particles with aerodynamic diameter less than $2.2 \mu \mathrm{m}$, which are mainly of anthropogenic origin and predominately from transport related sources. On the other hand, due to the meteorological reason and long-range transport during the wintertime, the PM concentrations remain much higher than the Bangladesh National Ambient Air Quality Standard (NAAQS).
\end{abstract}

Key words: Spatial distribution, Air particulate matter, Pollution

\section{INTRODUCTION}

Air pollution, especially due to fine particles has become a major environmental concern in urban areas world over, in view of its adverse health effects that have been associated with ambient fine particulate matter. Particulate matter (PM) is the term used for a mixture of solid particles and liquid droplets suspended in the air. These particulates may originate from a variety of sources, such as power plants, industrial processes, transports, brick kilns, biomass burning, wind blown dust, sea spray, and also they are formed in the atmosphere by transformation of gaseous emissions. The chemical and physical compositions of these particles depend on characteristics of the emission sources located around the area, time of year, and prevailing weather conditions. Size distribution of the particles follows a bimodal distribution with a valley around $2.5 \mu \mathrm{m}$. The mass of the particles is proportional to the area under the distribution within each size range. The Total Particulate Size (TSP) fraction ranges (also referred to as Suspended Particulate Matter or SPM) from 0 to $\sim 40 \mu \mathrm{m}$, the $\mathrm{PM}_{10}$ fraction ranges from 0 to $10 \mu \mathrm{m}$ and the $\mathrm{PM}_{2.5}$ size fraction ranges from 0 to $2.5 \mu \mathrm{m}$.

The characterization of these fine particles is very important for the regulators, and researchers due to their potential impact on human health, their ability to travel thousands of kilometers across countries, and their influence on climate forcing and global warming (IPCC 2001). In order to have an efficient Air Quality Management (AQM) system and also for regulatory purposes it is important to have reliable air quality data and its temporal and spatial distribution.

* Corresponding author: <swapanb@dhaka.net>.

${ }^{1}$ Clean Air and Sustainable Environment (CASE) Project, Department of Environment, Agargaon. Dhaka-1207, Bangladesh. 
In Bangladesh, the Department of Environment (DoE) is mandated by the Government for managing environmental issues including air pollution and its impact on human health, vegetation and structures, etc. Before 2002, the DoE used to measure total suspended particles (TSP) in a limited scale in different cities as part of their regulatory activity. With the inception of Air Quality Management Project (AQMP) in 2002, the DoE started measuring $\mathrm{PM}_{10}$ and $\mathrm{PM}_{2.5}$ fraction of the $\mathrm{PM}$ and other criteria pollutants for regulatory purposes as mentioned in the New National Ambient Air Quality Standards (BGD 1995). Since April 2002, the DoE is running a Continuous Air Monitoring Station (CAMS) at Shangshad Bhaban premises capable of monitoring all criteria pollutants except $\mathrm{Pb}$ and several Satellite Air Monitoring Stations (SAMS) for measuring only $\mathrm{PM}_{10}$ and $\mathrm{PM}_{2.5}$.

While, the Atomic Energy Centre, Dhaka (AECD) of Bangladesh Atomic Energy Commission (BAEC) is monitoring $\mathrm{PM}_{2.5}$ and $\mathrm{PM}_{2.5-10}$ as part of regional air pollution monitoring network of 15 countries in Southeast Asia and the Pacific under Regional Cooperative Agreement (RCA) with financial assistance from International Atomic Energy Agency (IAEA) (Hopke et al. 2008). Over the years both DoE and BAEC have got sufficient PM data to assess the trends and spatial distribution of fine PM.

It is also understood from different literatures that fine PM levels are quite high in Dhaka that have substantial public health impact. Therefore, only fine PM data have been analyzed in this work. Since data on fine particles are collected by different agencies using independent methodology as well as equipment, it is important to understand the quality of data collected for ensuring comparable data. Thus one of the objectives of the present work is to verify the data obtained from both the monitoring network. This paper also reports trend and spatial distribution of air particulate matter in Dhaka city and comparison of air quality data obtained from DoE and BAEC monitoring stations.

\section{MATERIALS AND METHODS}

Sampling site description

DoE sites: To satisfy the basic national needs for monitoring air quality and to control air pollution in the major cities of Bangladesh, the DoE has set up the first ever in the country, the continuous Air Quality Monitoring Station (CAMS) at the Sangsad Bhaban premises located at the heart of capital Dhaka city, since April 2002 and five Satellite Air Quality Monitoring Stations (SAMS) in 2005 at different locations of Dhaka city.

Continuous Air Monitoring Station: A Continuous Air Quality Monitoring Station (CAMS) was set up to monitor and evaluate the current air pollution levels in ambient air on a continuous basis. CAMS measures air pollutants such as $\mathrm{CO}, \mathrm{SO}_{2}, \mathrm{NOx}, \mathrm{O}_{3}, \mathrm{CH}_{4}$ 
and non-methane hydrocarbon by using multiple gas analyzers. Twenty four hr average concentration of $\mathrm{PM}_{2.5}$ and $\mathrm{PM}_{10}$ is also measured at CAMS using high $\mathrm{PM}_{10}$ and $\mathrm{PM}_{2.5}$ samplers. Furthermore, CAMS continuously measure Meteorological parameters such as wind direction horizontal and vertical wind speed, rainfall, relative humidity, atmospheric temperature, barometric pressure and solar radiation.

The monitoring station housed at Sangsad Bhaban area ideally represents average pollution levels in Dhaka city. This is the central air monitoring station in Dhaka. CAMS is located in an open, flat area approximately 150 meters away from the heavily trafficked Rokeya Sharani and 300 meters from Manik Mia Avenue. There are no significant local sources of air pollution such as construction or industrial activities in the immediate vicinity of CAMS. No large buildings available within the monitoring area of CAMS and no trees within 20 meter of sampling probe. The sampling inlets are located at the rooftop of a single storied building, which is about 3 meter above the ground. This sampling site can be classified as an urban location distanced from sources but representative of general population exposure and therefore can be treated as broadly representative of citywide neighborhood conditions. In the present study only particulate matter data obtained from the CAMS were used. High volume $\mathrm{PM}_{10}$ sampler was used collecting cumulative 24 hrs representative $\mathrm{PM}_{10}$ samples.

Satellite Air Monitoring Station (SAMS): There are four SAM stations and these are located at Tajgaon (BITAC), Rajarbag, Lalbag and Tongi. In all these stations, the samplings were done by using Air Metrics samplers and $\mathrm{PM}_{10}$ and $\mathrm{PM}_{2.5}$ samples were collected simultaneously. The description of the sampler is given elsewhere (Begum et al. 2005).

Tajgaon: This site is located in a heavy industrial area (BITAC) and a heavily trafficked road is 100 meter, away from the sampling location. Population density is lower as compared to the other sampling sites. Both industrial and motor vehicle sources make an important contribution to long-term and peak concentrations. One of the busiest bus terminals is located within less then 1 kilometer of the sampling site. A big metal workshop is also located within the immediate vicinity of the sampling site. The sampling probe is 7 meter above from the ground.

Rajarbag: This sampling site is located at the city center (Rajarbag Police Line) and can be treated as fully commercial and heavily traffic area. There are some large buildings situated within 50 meters. The sampler is located at the rooftop of a building 3 meter above the ground. This sampling site can be classified as an urban location representative of general population exposure in the city center e.g., pedestrian grounds and shopping areas.

Lalbag: The sampling site is a historical park with flat and open spaces located in southern part of the Dhaka City. The nearest road is not heavily trafficked but the 
whole area is very congested and densely populated. No large buildings or any nearby emission sources are available in the immediate vicinity of the site. However, some small cottage industries like plastic manufacturimg, bread and biscuit factories are located within 1 kilometer of sampling site. The sampling probe is almost 5 meter above the ground level.

Tongi: The characteristic of this site is almost same as Tejgaon site. The area is heavily industrial and a major inter-district highway i.e., Tongi-Mymensingh road is located within less than half a kilometer of the sampling site. Large number of diesel vehicles e.g., buses and trucks ply on this road almost 24 hours. Moreover, heavy industrial activity may also contribute to the pollutant concentrations at this sampling site. The sampling probe is almost 6 meter above the ground.

\section{Baec sampling sites}

The Atomic Energy Centre, Dhaka (AECD) of BAEC is operating two sampling sites (semi-residential and traffic hot spot) for collecting PM samples using a 'Gent' stacked filter sampler (Hopke et al. 1997) capable of collecting air particulate samples in coarse $(2.2-10 \mu \mathrm{m})$ and fine $(2.2 \mu \mathrm{m}$, ) size fractions together. $\mathrm{PM}_{10}$ concentration may be obtained by adding $\mathrm{PM}_{2.5}$ and $\mathrm{PM}_{10-2.5}$ concentrations. Generally, the samples were collected for a $24 \mathrm{~h}$ average period at least twice in a week (only week-days).

The hot spot site (HSD) is a high traffic area located at Farm Gate, Dhaka, adjacent to an intersection of several main roads typically carrying heavy traffic. The sampler was placed on the flat roof of the guardhouse of the Bangladesh Agricultural Research Council (BARC). The roof height was $3 \mathrm{~m}$ above the ground and the intake nozzle of the sampler was located $1.8 \mathrm{~m}$ above the roof. The intake was about $5 \mathrm{~m}$ away from the roadside. In the semi-residential area (SR) site, the sampler was placed on the flat roof of the Atomic Energy Centre, Dhaka (AECD) campus building. The roof height was $5 \mathrm{~m}$ and the intake nozzle of the sampler was located $1.8 \mathrm{~m}$ above the roof. The intake was about $80 \mathrm{~m}$ away from the roadside. The sampler was placed so that the airflow around it was unobstructed.

Location of the sampling stations in given is Fig. 1. It can be seen the sampling sites covers the overall geographical area of Dhaka city. 


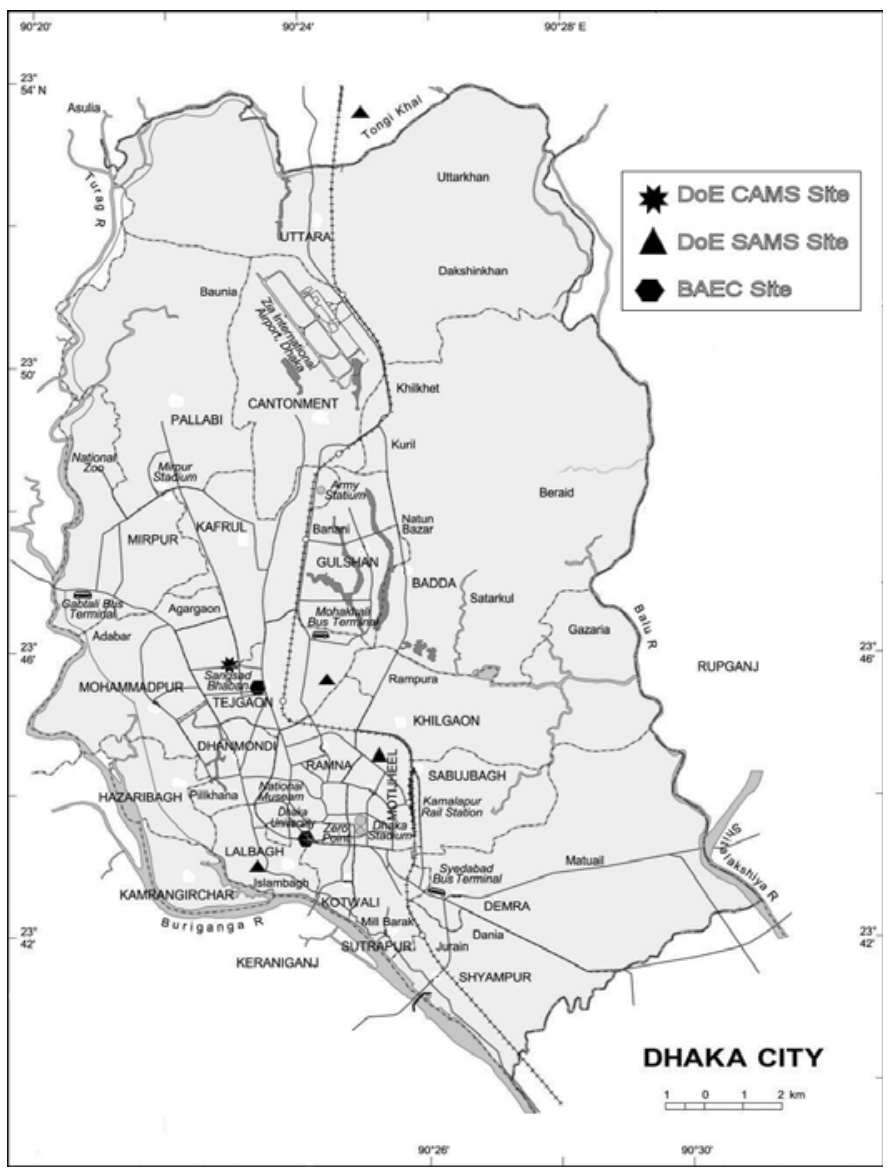

Fig. 1. Locations of sampling sites.

Description of samplers

Gent sampler: The Gent sampler collects samples in two fractions namely fine from 0-2.5 $\mu \mathrm{m}$ and coarse from 2.5-10. The description of the sampler is given elsewhere (Cahill et al. 1979). The initial filter used for coarse fraction is an $8 \mu \mathrm{m}$ pore $47 \mathrm{~mm}$ nuclepore filter and the second filter collecting fine fraction is a $0.4 \mu \mathrm{m}$ pore nuclepore filter.

High volume PM samplers in CAMS: In CAM station, Echotech Hi-Vol air samplers (Model GMW 1200) for $\mathrm{PM}_{10}$ and Partisol sampler (Model 2000) for $\mathrm{PM}_{2.5}$ were used in air particulate matter sampling, which is monitored by DoE. In this station, samples were collected for a $24 \mathrm{~h}$ period throughout the weeks including week-days and week-ends.

$P M_{10}$ sampler: The sampler draws ambient air at a constant flow rate of about $70 \mathrm{~m}^{3} / \mathrm{hr}$ into a specially shaped inlet where the suspended particulate matter is initially separated into one or more size fractions within the $\mathrm{PM}_{10}$ size range. The $\mathrm{PM}_{10}$ size range is then collected on a 
glass fiber filter over the sampling period of $24 \mathrm{hrs}$. The total volume of air sampled, measured at the actual ambient temperature and pressure, and is determined from the measured flow rate and the sampling time. The mass concentration of $\mathrm{PM}_{10}$ in the ambient air is computed as the total mass of collected particles in the $\mathrm{PM}_{10}$ size range divided by the volume of air sampled, and is expressed in micrograms per actual cubic meter $\left(\mu \mathrm{g} / \mathrm{m}^{3}\right)$.

$P M_{2.5}$ sampler: The Partisol Model 2000 air sampler is a flexible manual air sampling device can be easily fitted with sample inlets for $\mathrm{PM}_{2.5}, \mathrm{PM}_{10}$ and TSP monitoring. The sampler draws ambient air at a constant flow rate of about $1 \mathrm{~m}^{3} / \mathrm{hr}$ into a specially shaped inlet where the suspended particulate matter is separated into one or more size fractions within the $\mathrm{PM}_{2.5}$ size range and the $\mathrm{PM}_{2.5}$ fraction range is then collected on a $47 \mathrm{~mm}$ membrane filter over the sampling period of 24 hrs. The total volume of air sampled, measured at the actual ambient temperature and pressure, is determined from the measured flow rate and the sampling time.

Gravimetric mass measurement

Department of environment (DoE): Mass for the PM samples collected under the DoE air quality monitoring network was measured in the CAMS laboratory usually twice in a month. A Sartorius Micro-balance (Model MC 210S)) with $10 \mu \mathrm{g}$ readability was used for weighing the filters. Standard operation procedure (SoP) developed for weighing filters was followed. The aerosol masses of were determined by weighing the filters before and after exposure. A Po-210 (alpha emitter) electrostatic charge eliminator (STATICMASTER) was used to eliminate the static charge accumulated on the filters before each weighing.

Bangladesh atomic energy commission (BAEC): A Metler microbalance (Model MT5) having readability of $1 \mu \mathrm{g}$ was used for the gravimetric analysis and the quality assurance exercises. Standard operating procedure (SoP) developed in the laboratory was followed throughout the study. Before pre-weighing, the filters were inspected to assure that there are no pinholes, tears, creases, or other flaws, which may affect the collection efficiency of the filter.

The filter masses were determined by weighing the filters without exposing them. A Po-210 (alpha emitter) electrostatic charge eliminator (STATICMASTER) was used to eliminate the static charge accumulated on the filters before each weighing (Begum et al. 2006). Zero/span check was done before weighing for proper operation of the measurement system. Before and after the actual weighing, the balance was calibrated using secondary standard masses for quality control checks.

\section{RESULTS AND DISCUSSION}

Quality control in gravimetric analysis: Data quality objectives in any measurement usually specify the level of uncertainty in the data that the users are willing to accept. Since the PM measurement in CAM station and probably in other proposed station are based on the gravimetric analysis of air filters. Therefore, it is essentially required that the 
measurement of mass would be as accurate as possible to achieve the data quality objective. This needs for quality control in weighing of air filters both on pre- and post collection of the PM samples.

In order to perform ambient air sampling and mass analysis operations consistently, standard operating procedure (SoP) (Begum et al. 2006) must be followed during the air filter paper weighing to have quality control/quality assurance data. It is important to make sure that the results are free of bias and within statistical control (Biegalski 1999). In air particulate matter (APM) studies, there are three important points that influence the experimental outcome. These are the sampling methodology, the laboratory conditions and the verification of analytical results. So the laboratory condition is responsible for the variation of gravimetric mass. Contaminations, aerosol loss from a filter, electrostatic charging of filters or differences in humidity may cause the deviations from the real value (Almeida et al. 2003). The measurement uncertainties are the error associated with the laboratory activities. Air quality management system requires comparable air quality data to be collected for assessment and regulatory purposes. Thus it is necessary for any air quality-monitoring programme to ensure that all the data generate by any equipment comply with acceptable standard.

In view of ensuring data quality, a laboratory intercomparison was organized for understanding the degree of comparable weighing results that could be achievable from CAMS and BAEC laboratories. For this purpose, a set of three secondary laboratory standards (approximately 100, $200 \mathrm{mg}$ and $3 \mathrm{~g}$ ) was prepared from stainless steel wire (weights that does not change/influenced over a long time period) and those were weighted independently in the CAMS and the BAEC laboratories. The results of the intercomparison run are given in Table 1. The data show very good agreement in mean

Table 1. Comparison of weights of the three different lab standards measured at BAEC laboratory.

\begin{tabular}{lcccccc}
\hline \multirow{2}{*}{ Statistics } & \multicolumn{2}{c}{$\mathrm{S}-1(\mathrm{mg})$} & \multicolumn{2}{c}{$\mathrm{S}-2(\mathrm{mg})$} & \multicolumn{2}{c}{$\mathrm{S}-3(\mathrm{~g})$} \\
\cline { 2 - 7 } & AQMP & BAEC & AQMP & BAEC & AQMP & BAEC \\
\hline Average & 100.653 & 100.652 & 203.463 & 203.464 & 2.9959 & 2.9959 \\
Standard deviation & 0.010 & 0.003 & 0.010 & 0.003 & 0.0001 & 0.0001 \\
Median & 100.650 & 100.651 & 203.460 & 203.465 & 2.9959 & 2.9959 \\
Maximum & 100.680 & 100.660 & 203.490 & 203.472 & 2.9961 & 2.9960 \\
Minimum & 100.630 & 100.642 & 203.440 & 203.457 & 2.9958 & 2.9958 \\
\hline
\end{tabular}

and median weights of the laboratory standards between the measurements of two different independent laboratories. The standard deviation in the AQMP measurement is thrice as high as the BAEC measurement, which reflects the precision of the BAEC measurement is better than the AQMP results. This is due to the advantage that BAEC used a microbalance of $1 \mu \mathrm{g}$ readability whereas the AQMP weighing was done using microbalance of $10 \mu \mathrm{g}$ readability. 
Quality assurance in PM sampling

For the PM data used in present study three different types of samplers were used. Thus it was necessary to ensure that the samplers produce comparable data. At the CAMS site both $\mathrm{PM}_{10}$ and $\mathrm{PM}_{2.5}$ samples were collected by using FRM samplers but in SAMS sites those samples were collected using Airmatrics samplers, which is not a FRM sampler. On the other hand, at the BAEC site PM samples were collected using GENT sampler, which is also not a FRM sampler. Although GENT sampler is not a FRM sampler, but intercomperison study with Phillips beta gauge $\mathrm{PM}_{10}$ sampler and ASP/IMPROVE $\mathrm{PM}_{2.5}$ cut-point sampler showed good correlation (Hopke et al. 1997). It is seen that if the overloading is carefully addressed the GENT sampler provides aerodynamically well defined samples. It is also observed that GENT sampler collects less of the fine particles mass than the FRM samplers. The GENT sampler was typically operated at 16 to $18 \mathrm{lpm}$ resulting in an estimated $50 \%$ cut point of $2.2 \mu \mathrm{m}$ rather than $\mathrm{PM}_{2.5}$.

The characteristics of the MiniVol Portable Air Sampler were compared with GENT sampler by examining the reproducibility of the sample mass collection efficiency and the measured mass concentrations were also cross-checked. It was found that in case of $\mathrm{PM}_{10}$ both samplers collect almost same mass fraction when the GENT sampler was operated at 16 litre per minute flow rate. But in case of fine fraction, Airmetrics portable sampler collects $70 \%$ higher $\mathrm{PM}_{2.5}$ mass concentration compared to the GENT $\mathrm{PM}_{2.2}$ mass concentrations (Begum and Biswas 2005). This is because the GENT sampler was typically operated at 16 to $17 \mathrm{lpm}$ resulting in an estimated $50 \%$ cut point of $2.2 \mu \mathrm{m}$.

PM distribution in Dhaka city: Dhaka, the eighth largest mega city of the world, witnessed a very fast growth of urban population in recent times which contributed to rising demand for transport services, mainly the road transport. There has been a step rise in the heterogeneous mix of old technology vehicles on the city roads despite that the road space is narrowing and the traffic congestion reached to an unmanageable proportion. As a result the major traffic intersections in the city have turned to hot spots for air pollution due to vehicular emissions. Motorized transports of Dhaka are suspected to be the single largest contributor of air pollution in Dhaka. It is known that diesel exhaust contains harmful gases, liquid droplets and solid particles. The majority of the particles are sub-micron in size and are considered to be most damaging to human health. The pollutants of concern found in diesel exhaust are $\mathrm{PM}, \mathrm{NO}_{\mathrm{x}}$, hydrocarbon toxins such as polynuclear aromatics. The primary particles are emitted directly by vehicles; secondary particles are formed from the chemical oxidation of atmospheric gases. Oxides of sulphur and of nitrogen are precursors for secondary particles; reducing sulphur in diesel could lower the amount of sulphate-based particles. On the other hand, $\mathrm{CNG}$ vehicles also emit particles in sub-micron range which are also harmful for human. 
PM emission is generally attributed to engines design and maintenance, fuel consumption due to over-overfuelling, overloading, engines being underpowered and poorly maintained, lubricant oil consumption and sulphur content of the fuel (Kundu et al. 2006). In case of engines where other design parameters are addressed, higher the content of sulphur, higher is the PM emission. This is because, due to high sulphur content, some of the post combustion emission control devices cannot be used. In addition, PM emission from a diesel vehicle is a function of the vehicle speed. The optimum steady speed for emissions, which is usually in excess of $60 \mathrm{~km}$ per hour, is rarely achievable given the traffic situation in Dhaka city.

Therefore the assessment focuses on the particle mass concentrations data from 2002 - 2007. The co-located PM samples were collected from different sites throughout the year. Tables 3 and 4 provide the details on the number of samples collected in each size range during each of year of the study areas.

Table 3. Statistical values of $\mathbf{P M}_{10}$ mass concentrations of all sites over the period of 2002 to 2007.

\begin{tabular}{lccccc}
\hline \multicolumn{1}{c}{ Sampling sites } & $\begin{array}{c}\text { Number of } \\
\text { samples }\end{array}$ & Minimum & Maximum & Average & SD \\
\hline CAMS, Shangsad Bhaban & 1176 & 15.0 & 543 & 130 & 87.0 \\
Hot spot site & 366 & 16.4 & 942 & 134 & 90 \\
Semi-residential site & 479 & 5.52 & 409 & 81.0 & 56.1 \\
Tajgaon & 48 & 32.0 & 509 & 155 & 123 \\
Tongi & 68 & 21.0 & 484 & 145 & 105 \\
Ragarbaj & 78 & 28.0 & 586 & 189 & 115 \\
Lalbag & 71 & 47.0 & 461 & 178 & 106 \\
\hline
\end{tabular}

Table 4. Statistical values of $\mathbf{P M}_{2.5}$ mass concentrations of all sites over the period of 2002 to 2007.

\begin{tabular}{lccccc}
\hline \multicolumn{1}{c}{ Sampling sites } & $\begin{array}{c}\text { Number of } \\
\text { samples }\end{array}$ & Minimum & Maximum & Average & SD \\
\hline CAMS, Shangsad Bhaban & 1130 & 9.00 & 405 & 78.3 & 61.9 \\
Hot spot site & 366 & 8.21 & 371 & 41.2 & 35.1 \\
Semi-residential site & 477 & 2.34 & 220 & 29.1 & 20.1 \\
Tajgaon & 61 & 11.0 & 364 & 99.9 & 76.3 \\
Tongi & 62.0 & 19.0 & 376 & 103 & 78.6 \\
Ragarbaj & 101 & 15.0 & 366 & 91.2 & 66.7 \\
Lalbag & 74 & 28.0 & 349 & 99.0 & 71.3 \\
\hline
\end{tabular}

Bangladesh is a developing country, and there has been high growth in the industrial sector surrounding the Dhaka city in recent past (Begum et al. 2008). The Government has taken different steps to reduce the particulate matter (PM) concentrations, as PM is the criteria pollutant (Begum et al. 2006). Fig. 2 shows the distributions of $\mathrm{PM}_{2.5}$ and $\mathrm{PM}_{10}$ mass of the study areas within Dhaka city in the form of box and whisker plots. 

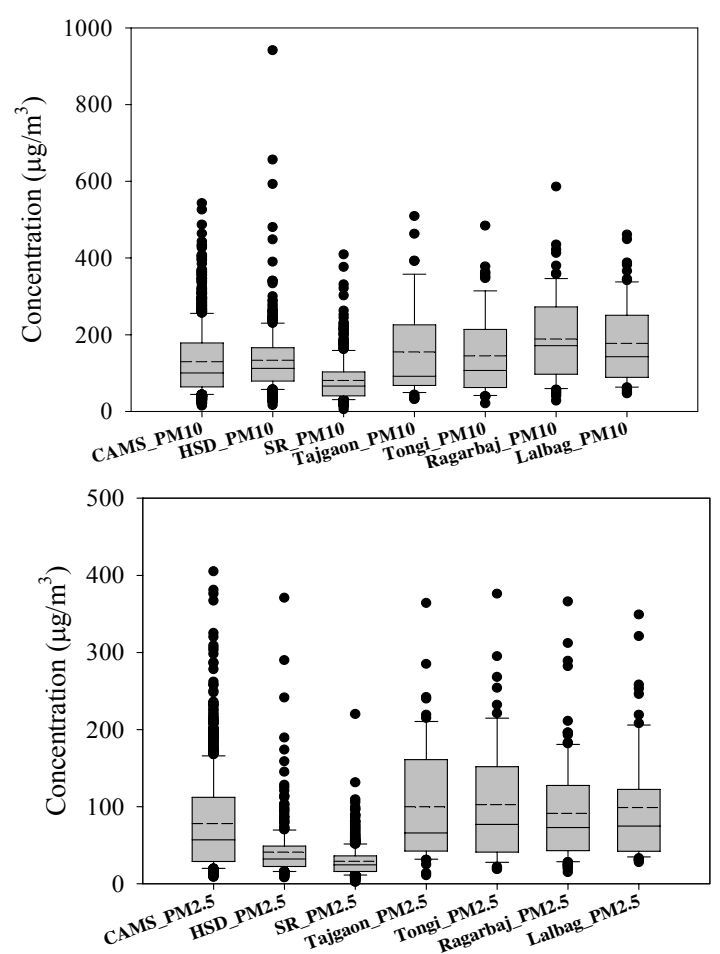

Fig. 2. Box and whisker plots of the distributions of $\mathrm{PM}_{10}$ and $\mathrm{PM}_{2.5}$ in different sites in Dhaka city.

The median, $10^{\text {th }}$ and $90^{\text {th }}$ percentile limits, outliers, median (solid line), and mean (dotted lines) are shown. The Bangladesh National Ambient Air Quality Standard (BNAAQS) for annual average $\mathrm{PM}_{2.5}$ is $15 \mu \mathrm{g} / \mathrm{m}^{3}$ while the $24 \mathrm{hr}$ standard is $65 \mu \mathrm{g} / \mathrm{m}^{3}$ and $\mathrm{PM}_{10}$ is $50 \mu \mathrm{g} / \mathrm{m}^{3}$ while the $24 \mathrm{hr}$ standard is $150 \mu \mathrm{g} / \mathrm{m}^{3}$. It was found that both $\mathrm{PM}_{2.5}$ and $\mathrm{PM}_{10}$ fractions are much higher that the BNAAQS values. Although the government has taken several policies in order to reduce the PM pollution but these are not enough to control the PM emissions. It was found from source apportionment study, for fine fractions that the main contributors are motor vehicles and brick kilns together with long range transport of fine PM (Begum et al. 2008). On the other hand, soil dusts including road dust are the main contributor for $\mathrm{PM}_{10}$ fractions. The fine mass concentration has varied depending on the locations. The fine mass concentrations may become high due to high vehicular contributions and also other anthropogenic activities such as diesel powered generators, construction activities, small industries etc.

Fig. 3 represents the box-whisker plots of all the fine PM sampling sites. It was found that the fine PM concentrations would exceed the latest Bangladesh National Ambient Air Quality Standard and also World Health Organization guidelines. The increases in coal combustion in bricks, traffic in the urban area and other fuel causing economic activities 
related to population increase are likely reasons for high pollution. It is noticeable that during the wintertime the PM concentrations register much higher amount due to local weather condition as well as long-range transport (Begum et al. 2009).
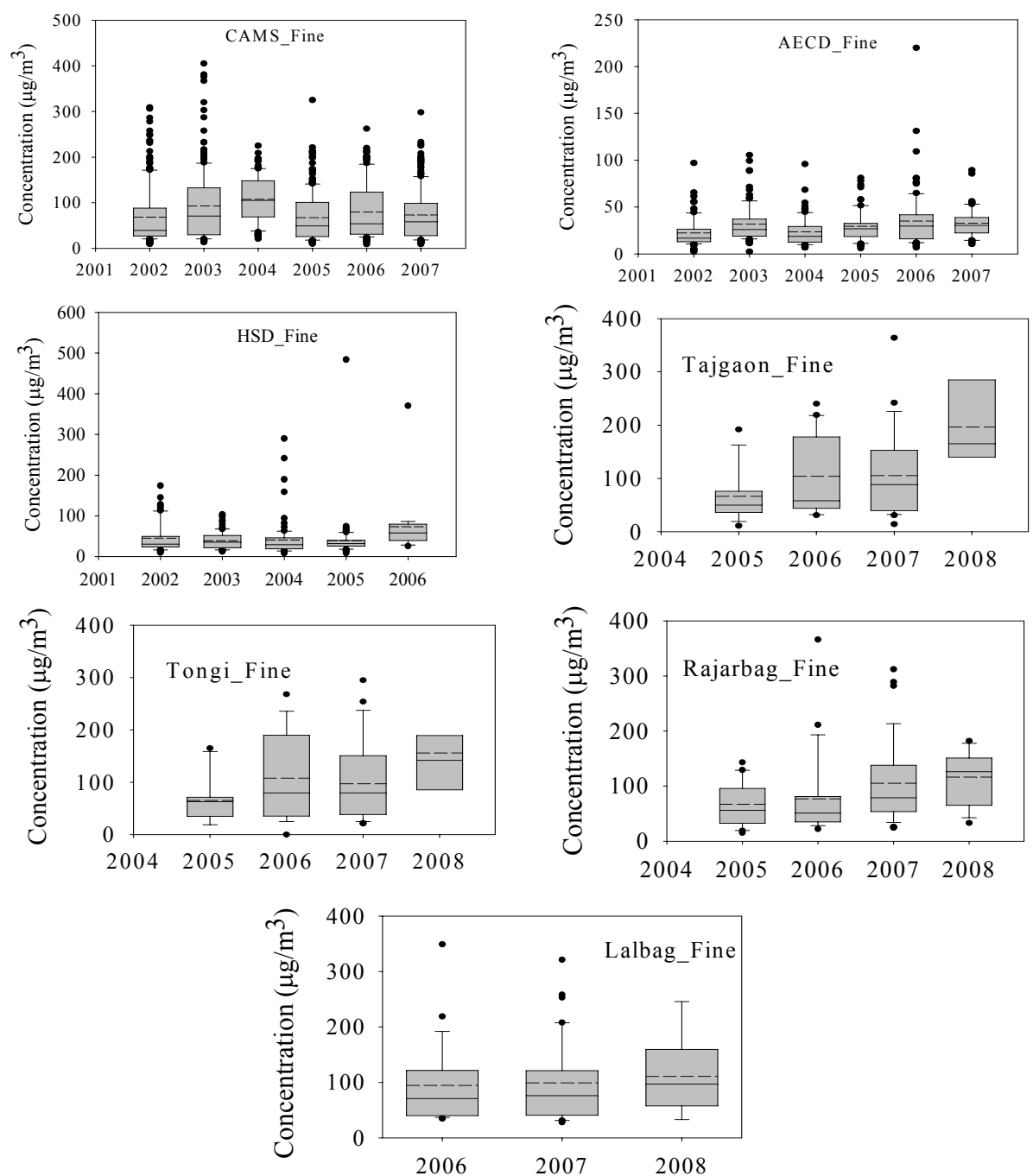

Fig. 3. Box-whisker plots of the distributions of the fine mass concentration over the last $2002-2008$.

Fig. 4 represents the box-whisker plots of all the $\mathrm{PM}_{10}$ sampling sites. It has found that the $\mathrm{PM}_{10}$ concentrations would exceed the latest Bangladesh National Ambient Air Quality Standard and also World Health Organization guidelines (WHO, 2005). Because of the proximity of major roadways in the monitoring sites (except semi-residential site), the influence of traffic induced coarse dust from abrasion and resuspension is obvious. 
This is plausible because mechanically produced particles, and in particular resuspension, depend not only on the vehicle frequency but also on the condition of the roadway (e.g. clean/dirty, wet/dry). The concentrations of $\mathrm{PM}_{10}$ vary due to local impact but the patterns of variation of mass concentrations are more or less same in all sites.
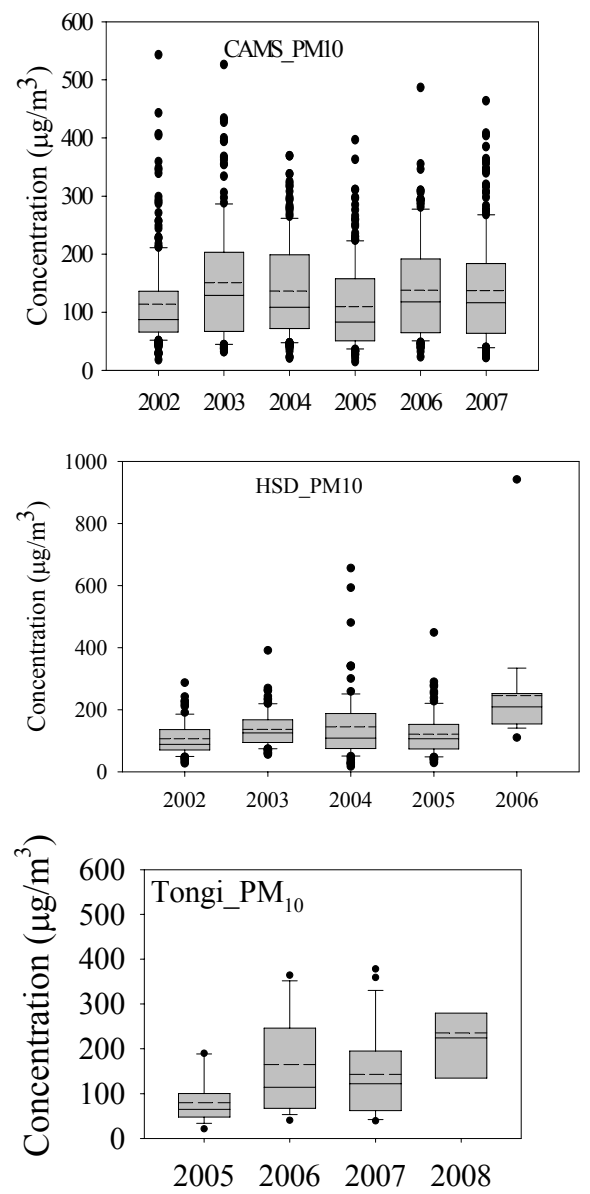
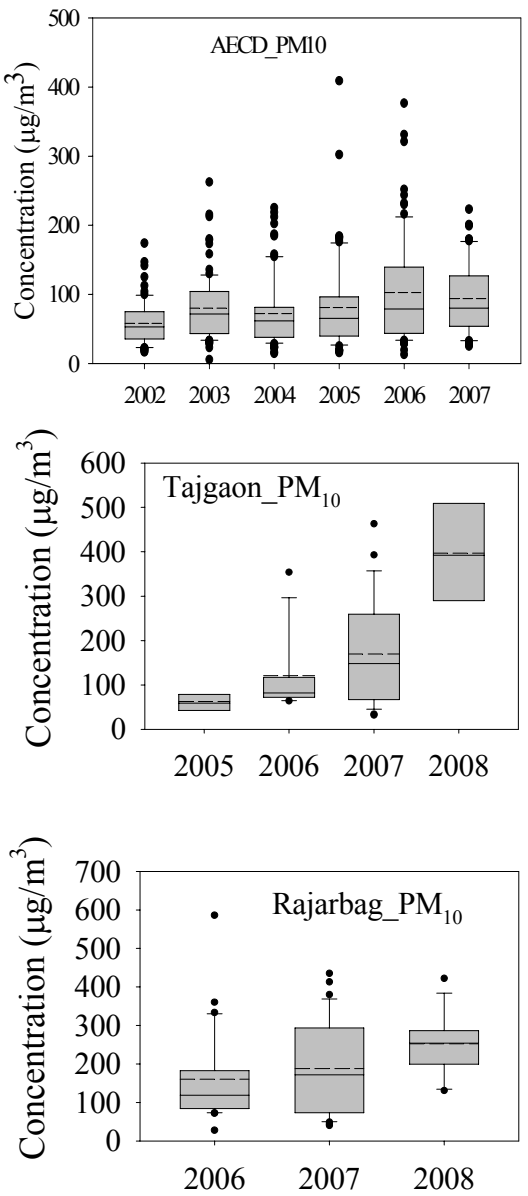

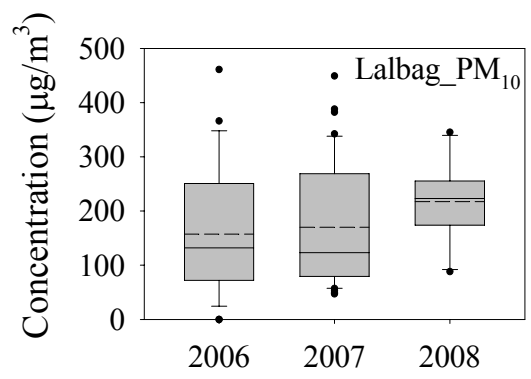

Fig. 4. Box-whisker plots of the distributions of the $\mathrm{PM}_{10}$ mass concentration over the last 2002-2008. 
From the time series (Fig. 5) of fine mass concentrations, it is evident that during the rainy season, fine mass concentration meets the ambient air quality standard.

Table 5. Fine air particulate mass concentration during different periods $\left(\mu \mathrm{g} / \mathrm{m}^{3}\right)$.

\begin{tabular}{lccccccccccccc}
\hline \multirow{2}{*}{ Site } & \multicolumn{2}{c}{2002} & \multicolumn{2}{c}{2003} & \multicolumn{2}{c}{2004} & \multicolumn{2}{c}{2005} & \multicolumn{2}{c}{2006} & \multicolumn{2}{c}{2007} \\
\cline { 2 - 12 } & Wet & Dry & Wet & Dry & Wet & Dry & Wet & Dry & Wet & Dry & Wet & Dry \\
\hline HSD & 30.2 & 59.0 & 24.7 & 45.0 & 35.1 & 58.3 & 25.2 & 66.8 & & & & \\
SR & 15.0 & 51.8 & 21.1 & 32.5 & 13.8 & 32.5 & 20.0 & 68.3 & 14.4 & 47.5 & 18.7 & 60.2 \\
CAMS & 30.0 & 182 & 26.1 & 120 & 28.7 & 139 & 28.3 & 136 & 33.7 & 160 & 24.6 & 124 \\
Tajgaon & & & & & & & 43.4 & 175 & 45.1 & 212 & 41.4 & 190 \\
Tongi & & & & & & & 48.7 & 192 & 37.3 & 195 & 37.8 & 185 \\
Rajarbag & & & & & & & 33.6 & 103 & 48.3 & 214 & 48.5 & 130 \\
Lalbag & & & & & & & & 136 & 51.6 & 216 & 51.5 & 128 \\
\hline
\end{tabular}

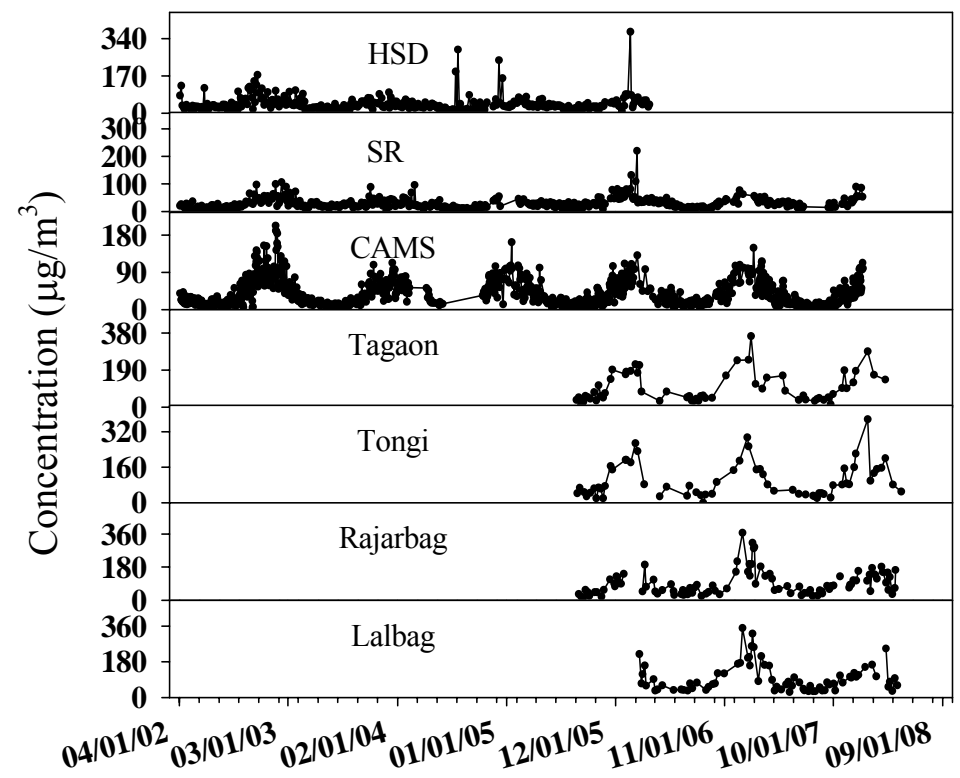

Fig. 5. Time variations for fine mass concentrations of the study areas in Dhaka.

However, during the dry season, the values go up 5 - 7 times higher than the rainy season (Table 5). The reasons for the high peaks during the winter are not only caused by seasonal fluctuations of the emissions, but also by meteorological effects. Because winter 
season is characterized by dry soil conditions, low relative humidity, scanty rainfall and low northwesterly prevailing winds (Fig. 6).
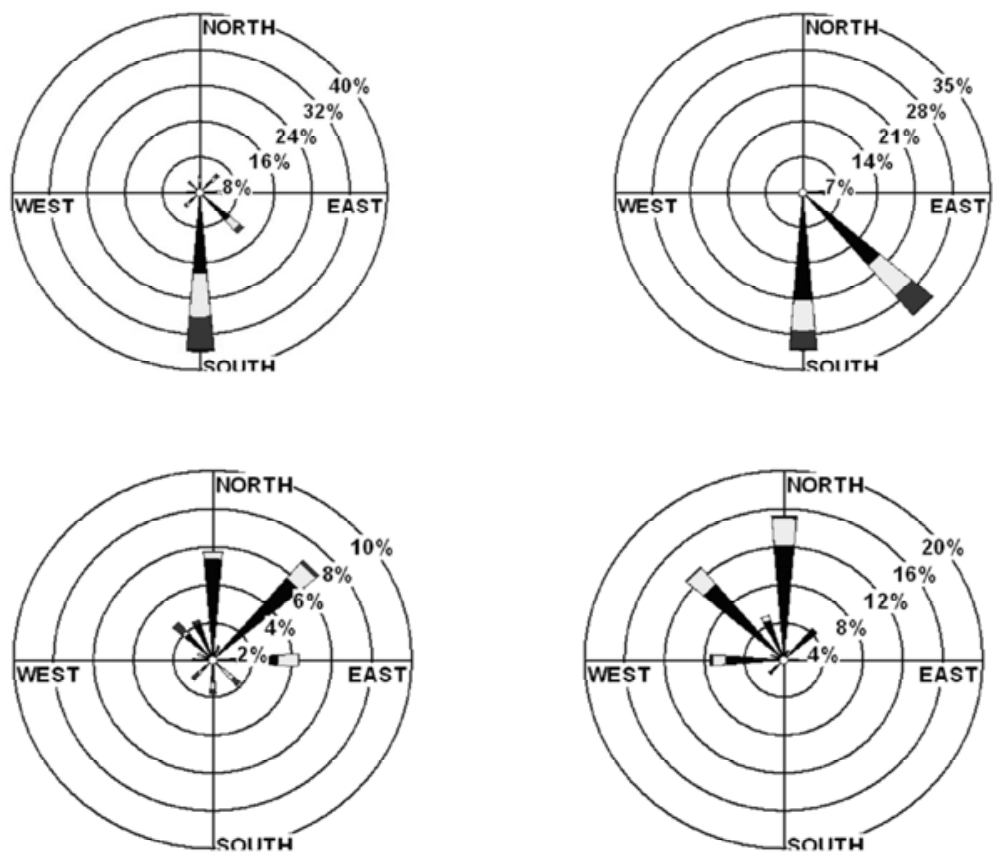

Fig. 6. Seasonal wind direction (Pre-monsoon, monsoon, post-monsoon and winter) at Dhaka based on wind speed data.

\section{CONCLUSION}

The temporal and spatial pattern analysis of PM data is particularly useful for source identification. Moreover, consideration of spatial and temporal scales helps to focus PM management strategies on the effects of concern. It has been found that about $30-50 \%$ of the $\mathrm{PM}_{10}$ mass (depending on location) in Dhaka is due to fine particles with aerodynamic diameter less than $2.5 \mu \mathrm{m}$, which are mainly of anthropogenic origin and predominately from transport related sources. Although there is large temporal variation in both $\mathrm{PM}_{10}$ and $\mathrm{PM}_{2.5}$ levels spatial variation across is rather limited. The government's actions so far which among others include banning of two-stroke three wheeler baby taxis and imposing restrictions on the registration of diesel run commercial vehicles have proved insufficient to improve the ambient air quality. As a result, the concentration of fine particulate mass is on the rise (Fig. 4).

The PM concentrations increase during the dry winter-time due to the meteorological condition (Begum et al. 2008) and there are indications (Begum et al. 2009) that these 
pollutants may also be important for the vehicle. Therefore, actions to reduce air pollution in Dhaka exacerbated by trans-boundary contribution merit special attention.

\section{REFERENCES}

Almeida S. M., M. A. Reis, M. C. Freitas, and C. A. Pio. 2003. Quality assurance in elemental analysis of airborne particles. Nuclear Instruments and methods (B) 207: 434-446.

Begum B. A., and S. K. Biswas. 2005. Comparison of PM collection efficiency of Gent and Airmatrics MiniVol Portable Air Sampler. Nuclear Science and Application, I14: 79-83.

Begum B. A., S. Akhter, L. Sarker, and S. K. Biswas. 2006. Gravimetric analysis of Air Filters and Quality Assurance in Weighing. Nuclear Science and Applications 15: 36-41.

Begum B. A., S. K. Biswas, and P. K. Hopke. 2006. Temporal variations and spatial distribution of ambient $\mathrm{PM}_{2.2}$ and $\mathrm{PM}_{2.2-10}$ concentrations in Dhaka, Bangladesh. Science of the Total Environment. 358: 36-45.

Begum B. A., S. K. Biswas, and P. K. Hopke. 2006. Impact of banning of Two Stroke Engines on airborne particulate matter concentrations in Dhaka, Bangladesh. J. Air and Waste Management Association 56, 85-89.

Begum B. A., S. K. Biswas, and P. K. Hopke. 2008. Assessment of trends and present ambient concentrations of PM2.2 and PM10 in Dhaka, Bangladesh. Air Quality and Atmospheric Health 1: 125-133.

Begum B. A., S. K. Biswas, and P. K. Hopke. 2008. Assessment of trends and present ambient concentrations of $\mathrm{PM}_{2.2}$ and $\mathrm{PM}_{10}$ in Dhaka, Banglaesh. Air Qual. Atmos. Health DOI 10.1007/s11869-008-0018-7.

Begum B. A., S. K. Biswas, and P. K. Hopke. 2010. Identification of fine and coarse particulate matter Dhaka, Bangladesh. Aerosol and Air Quality Research, 10: 345-353.

Begum B. A., S. K. Biswas, G. G. Pandit, S. Waheed, M. C. S. Seneviratne, D. D. Cohen, and P. K. Hopke. 2009. Long Range Transport of Anthropogenic Pollution in the Asian Region. Atmospheric Pollution Research.

Bangladesh Air Quality and Vehicular Emission Std. 1995. Bangladesh Gazette. p. 1568.

Biegalski S. R. 1999. Elemental Analysis of airborne particles. Gordon and Breach Science Publishers, USA, Chapter 7: 255.

Cahill T. A., R. A. Eldred, J. B. Barone, and L. L. Ashbaugh. 1979. Ambient aerosol sampling with stacked filter units. Report No. FHWA-RD-78-178, US. Department of Transportation, Washington D.C. p. 73.

Hopke P. K., D. D. Cohen, B. A. Begum, S. K. Biswas, B. Ni, G. G. Pandit, M. Santoso, Y.-S. Chung, P. Davy, A. Markwitz, S. Waheed, N. Siddique, F. L. Santos, P. C. B. Pabroa, M. C. S. Seneviratne, W. Wimolwattanapun, S. Bunprapob, T. B. Vuong, and A. Markowicz. 2008. Urban Air Quality in the Asian region. Science of the Total Environ. 404: 103-112.

Hopke P. K., Y. Xie, T. Raunemaa, S. Biegalski, S. Landsberger, W. Maenhaut, P. Artaxo, and D. Cohen. 1997. Characterization of Gent stacked filter unit PM10 sampler. Aerosol Science and Technology, 27: 726-735.

Hopke P. K., Y. Xie, T. Raunermaa, S. Biegalski, S. Landsberger, W. Maenhaut, P. Artaxo, and D. Cohen. 1997. Characterization of the Gent Stacked Filter Unit PM10 Sampler, Aerosol Science and Technology, 27: 726-735.

IPCC. 2001. The third assessment report of WORKING group I of the intergovernmental panel on climate change, technical summary, lead authors, D.L. Albritton (USA), L.G. Meira Filho (Brazil), Shanghai. 10: 44-45. 
Khaliquzzaman M., 2003. An Assessment of the Impact of Removal of Baby Taxis on Air Quality in Dhaka, Personal Communication, Consultant, World Bank, Dhaka Office.

Kundu P. C., B. Tarafder, M. R. U. Mollah, and S. R. Hayat. 2006. Radside vehicle emission testing program in Dhaka, AQMP-DoE: TECDOC NO.01/06.

Who. 2005. Air Quality Guidelines for Particulate matter, Ozone, Nitrogen dioxide and Sulfur dioxide. WHO/SDE/PHE/OEH/06.02. p. 8.

(Received revised manuscript on 10 November, 2009) 